\title{
Measurement and Characterization of the Apparent Viscosity of Fe-C Melts during Solidification
}

\author{
Yan-Ling ZHANG, Qi LI, * Zhuo-Qing AN and Zhan-Cheng GUO \\ State Key Laboratory of Advanced Metallurgy, University of Science and Technology Beijing, Xueyuan Road 30, Haidian Dis- \\ trict, Beijing, 100083 China.
}

(Received on July 1, 2015; accepted on August 24, 2015)

\begin{abstract}
The rheology of $\mathrm{Fe}-\mathrm{C}$ melts during solidification can give important insight into the process operations and product quality of the resulting alloys. Here, we investigated the apparent viscosity of Fe-C melts during solidification. The testing spindle of the traditional rotation method for measuring the viscosity of liquids was improved so that it could be used to measure the apparent viscosity of Fe-C melts during solidification. Further, the apparent viscosity of $\mathrm{Al}_{2} \mathrm{O}_{3}$ particles in methyl silicon oil, a representative liquidsolid slurry system, was measured. The effects of the particle fraction, particle shape and particle size on the apparent viscosity of the slurry were examined and the viability of a viscosity prediction model was tested. Finally, the apparent viscosity of $\mathrm{Fe}-\mathrm{C}$ melts during solidification was measured. Our results showed that the apparent viscosity of $\mathrm{Fe}-\mathrm{C}$ melts during solidification increased with increasing cooling rate and decreasing shear rate. The effect of precipitated particle structures on the apparent viscosity of $\mathrm{Fe}-\mathrm{C}$ melts during solidification was similar to the effect that $\mathrm{Al}_{2} \mathrm{O}_{3}$ particles had on the methyl silicon oil- $\mathrm{Al}_{2} \mathrm{O}_{3}$ particle system. The viscosity model to predict the apparent viscosity of Fe-C melts under different solidification conditions was proposed.
\end{abstract}

KEY WORDS: Fe-C melts; solidification process; apparent viscosity; viscosity model of Fe-C melts.

\section{Introduction}

Solidification is a key step in the processing of metal materials. The rheological behavior of metal melts during solidification can provide remarkable insight into the process operations and the product quality of the resulting alloys. In the steelmaking process, the formation of product defects, such as porosity, element segregation and shrinkage, is closely related to the viscosity of the $\mathrm{Fe}-\mathrm{C}$ melts during solidification because the viscosity of the melt controls the fluidity and the rate of transport of the liquid metal. ${ }^{1)}$ Therefore, determining the apparent viscosities of $\mathrm{Fe}-\mathrm{C}$ melts during solidification is of great significance when guiding the production of these materials.

There have been many previous studies investigating the viscosity of pure liquid metals as well as non-ferrous and low melting point metals in the semi-solid state, providing a wide library of experimental data in the literature. ${ }^{2-5)}$ However, the data on the apparent viscosity of $\mathrm{Fe}-\mathrm{C}$ melts during solidification is extremely limited due to the experimental difficulties such as the poor availability of rheological instruments for use at high temperatures and a measurement spindle that does not react with the molten $\mathrm{Fe}-\mathrm{C}$ alloy. Shibutani et $a l .{ }^{6}$ ) measured the apparent viscosity of $\mathrm{Fe}-\mathrm{C}(3$ and $4 \% \mathrm{C})$ and $\mathrm{Fe}-\mathrm{Cr}-\mathrm{Ni}-\mathrm{C}$ alloys in state where liquid and solid phases coexisted using rotating coaxial

* Corresponding author: E-mail: huojianliqi@163.com

DOI: http://dx.doi.org/10.2355/isijinternational.ISIJINT-2015-389 cylinder viscometer at a high shear rate (range from 158 to $377 \mathrm{~s}^{-1}$ ). It was found that the viscosity depended on the solid fraction, the cooling rate, and the shear rate, and the viscosity was influenced more by the cooling rate than the shear rate. Hiral et al. ${ }^{7)}$ quantified the effect of chemical compositions on viscosity of several semi-solid alloys such as $\mathrm{Al}-\mathrm{Cu}, \mathrm{Al}-\mathrm{Si}, \mathrm{Cu}-\mathrm{Sn}$, and $\mathrm{Fe}-\mathrm{C}(0.8$ and $2.5 \% \mathrm{C})$. In this research, a uniform predicting model on apparent viscosity was obtained, where the density of alloys (termed as $\rho_{m}$ in that research) was utilized as an important parameter to characterize the effect of chemical compositions on apparent viscosity of semi-solid alloys.

Numerous theoretical and semi-theoretical models ${ }^{8-11)}$ have been proposed to predict the viscosity of solid-liquid mixtures and suspensions. However, most of these models have major limitations when applied to practical situations. For example, the model proposed by Einstein ${ }^{8,9)}$ requires a uniform distribution of rigid, spherical particles with the same diameter dispersed in a liquid matrix. This model is only applicable to a narrow solid fraction range. Happel's model $^{10)}$ and Thomas's model ${ }^{11)}$ only consider the influence of the solid fraction without considering the impact of external factors. Currently, the model proposed by Mori and Ototake $^{12)}$ is most often used to characterize the apparent viscosity of metals in the semi-solid state ${ }^{7,13-15)}$ (Eq. (1)):

$$
\eta=\eta_{L}\left[1+\frac{\bar{d} \cdot S_{\mathrm{r}}}{2} /\left(\frac{1}{f_{s}}-\frac{1}{f_{\text {scr }}}\right)\right]
$$


where, $\eta$ and $\eta_{L}$ are the viscosity of the solid-liquid mixture and liquid, respectively, $\bar{d}$ and $S_{\mathrm{r}}$ are the equivalent diameter of the solid particle and the ratio of surface area to volume, respectively, $f_{s}$ is the solid fraction, $f_{\text {scr }}$ represents the maximum amount of solid that the liquid could accommodate before the viscosity becomes "infinite," referred to as the critical solid fraction.

The Mori and Ototake model considers the effects of the size and shape of the solid particles on the viscosity of the mixture and is applicable over a wide solid fraction range. By using the Mori and Ototake model structure, Hiral et al. ${ }^{7)}$ developed a model for predicting the apparent viscosities of $\mathrm{Al}, \mathrm{Cu}$, and Fe-based semi-solid alloys and Matsuzaki et $a l .{ }^{13)}$ developed a slag viscosity estimation model with respect to the deposition of the solid phase.

For a solid-liquid slurry or suspension, if the size and shape of the solid particles in the system do not change, Eq. (1) can be used to describe the variation in the viscosity of the melt. However, if the size and shape of the solid particles are constantly changing along with increasing solid fraction, $\bar{d} \cdot S_{\mathrm{r}}$ in Eq. (1) can be replaced by the geometry parameter "P", a physical property value proportional to $\bar{d} \cdot S_{\mathrm{r}}$, for a more accurate model ${ }^{12)}($ Eq. (2)).

$$
\eta=\eta_{L}\left[1+\frac{\mathrm{P}}{2} /\left(\frac{1}{f_{s}}-\frac{1}{f_{\text {scr }}}\right)\right]
$$

Here, we focused on measuring and characterizing the apparent viscosity of $\mathrm{Fe}-\mathrm{C}$ melts during solidification. We modified the testing spindle of a traditional rotation viscosity measuring system so that it could be used to measure the apparent viscosity of $\mathrm{Fe}-\mathrm{C}$ melts during solidification. Next, we measured the apparent viscosity of a model system, a methyl silicon oil- $\mathrm{Al}_{2} \mathrm{O}_{3}$ particle mixture, to allow us to examine the effects of the solid particle fraction, particle size, and particle shape on the apparent viscosity of the system as well as the reliability of a viscosity prediction model based on Eq. (1). Finally, the apparent viscosity of $\mathrm{Fe}-\mathrm{C}$ melts during solidification was measured and the effects of the solid fraction, shear rate, cooling rate and carbon content were investigated. A viscosity prediction model based on Eq. (2) was derived from our results.

\section{Experimental}

\subsection{Sample Preparation}

$\mathrm{Al}_{2} \mathrm{O}_{3}$ particles in methyl silicon oil were used as a model suspension for measuring the apparent viscosity of solidliquid systems. The average size and specific surface area of the $\mathrm{Al}_{2} \mathrm{O}_{3}$ particles were measured by laser particle size analyzer (LMS-30 Micron Sizer, Seishin Enterprise Co., Ltd., Tokyo, Japan; Table 1). Particles in samples 1, 2, and 4 were irregularly shaped, while the particles in sample 3 were nearly spheroidal and the particles in sample 5 were spheres (Fig. 1).

Prior to the apparent viscosity measurements of $\mathrm{Fe}-\mathrm{C}$ melts during solidification, the chemical reagents for each mixture, namely, metallic Fe powder (AR) and graphite $\mathrm{C}$ (CP, purity greater than $99.8 \%$ ) were mixed thoroughly at the desired mass percent in a mortar. The mixed samples were packed into an $\mathrm{Al}_{2} \mathrm{O}_{3}$ crucible and pre-melted in an
Table 1. Geometry parameters of $\mathrm{Al}_{2} \mathrm{O}_{3}$ particles.

\begin{tabular}{cccc}
\hline No. & Particle type & $\begin{array}{c}\text { Average particle } \\
\text { size }(\mu \mathrm{m})\end{array}$ & $\begin{array}{c}\text { Volume-based } \\
\text { specific surface } \\
\left(\mathrm{m}^{-1} / 10^{-6}\right)\end{array}$ \\
\hline 1 & 2.3 & 3.739 \\
2 & & 41 & 0.184 \\
3 & $\mathrm{Al}_{2} \mathrm{O}_{3}$ & 41 & 0.180 \\
4 & & 120 & 0.062 \\
5 & & 4000 & 0.0015 \\
\hline
\end{tabular}
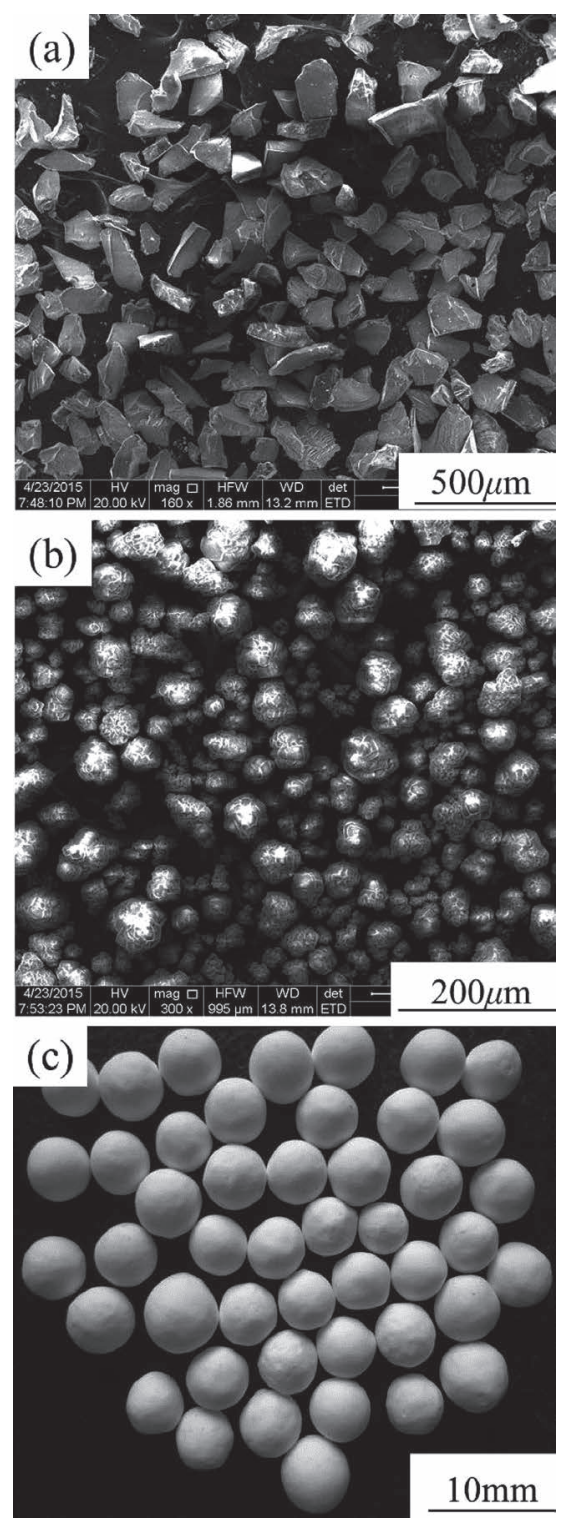

Fig. 1. Microphotographs of $\mathrm{Al}_{2} \mathrm{O}_{3}$ particles. (a) Sample 4, irregularly shaped particles. Representative of samples 1 and 2 as well. (b) Sample 3, spheroid type particles. (c) Sample 5, spherical particles.

induction furnace in an argon (Ar) atmosphere. After premelting the mixture, a small amount of the sample was taken to confirm the composition using chemical analysis (Table 2), while the remaining sample was preserved in a desiccator. 


\subsection{Experimental Procedure}

Viscosity measurements were carried out using the internal rotating cylinder method (Searle's method) with a Brookfield digital viscometer (Brookfield, Engineering Laboratories, Inc., Middleboro, MA). Figure 2(a) shows the apparatus used in the experiments, consisting of a rotating system, a heating system, and a measuring system. An

Table 2. Experimental conditions used in testing the apparent viscosity of $\mathrm{Fe}-\mathrm{C}$ melts.

\begin{tabular}{|c|c|c|c|c|c|}
\hline Group & Alloy & $\begin{array}{c}\text { Liquidus } \\
\text { temperature } \\
\left({ }^{\circ} \mathrm{C}\right)\end{array}$ & $\begin{array}{l}\text { Solid } \\
\text { fraction at } \\
\text { eutectic } \\
\text { point }\end{array}$ & $\begin{array}{l}\text { Cooling } \\
\text { rate } \\
\left({ }^{\circ} \mathrm{C} / \mathrm{min}\right)\end{array}$ & $\begin{array}{c}\text { Shear } \\
\text { rate }\left(\mathrm{s}^{-1}\right)\end{array}$ \\
\hline \multirow{3}{*}{ I } & \multirow{3}{*}{$\mathrm{Fe}-2.17 \% \mathrm{C}$} & \multirow{3}{*}{1370} & \multirow{3}{*}{0.950} & \multirow{3}{*}{5} & 12.7 \\
\hline & & & & & 19.1 \\
\hline & & & & & 25.4 \\
\hline \multirow{5}{*}{ II } & \multirow{5}{*}{$\mathrm{Fe}-2.40 \% \mathrm{C}$} & \multirow{5}{*}{1350} & \multirow{5}{*}{0.851} & 2 & 25.4 \\
\hline & & & & 5 & 25.4 \\
\hline & & & & 8 & 25.4 \\
\hline & & & & 5 & 12.7 \\
\hline & & & & 5 & 19.1 \\
\hline III & $\mathrm{Fe}-2.53 \% \mathrm{C}$ & 1339 & 0.795 & 2 & 25.4 \\
\hline \multirow{4}{*}{ IV } & \multirow{4}{*}{$\mathrm{Fe}-2.90 \% \mathrm{C}$} & \multirow{4}{*}{1304} & \multirow{4}{*}{0.636} & 5 & 12.7 \\
\hline & & & & 5 & 19.1 \\
\hline & & & & 5 & 25.4 \\
\hline & & & & 8 & 25.4 \\
\hline $\mathrm{V}$ & $\mathrm{Fe}-3.00 \% \mathrm{C}$ & 1295 & 0.593 & 1 & 19.1 \\
\hline \multirow{3}{*}{ VI } & \multirow{3}{*}{$\mathrm{Fe}-3.81 \% \mathrm{C}$} & \multirow{3}{*}{1212} & \multirow{3}{*}{0.245} & \multirow{3}{*}{5} & 12.7 \\
\hline & & & & & 19.1 \\
\hline & & & & & 25.4 \\
\hline
\end{tabular}

electric resistance furnace with $\mathrm{U}$-shape $\mathrm{MoSi}_{2}$ heating elements was used to heat the system. A Pt- $6 \% \mathrm{Rh} / \mathrm{Pt}-30 \% \mathrm{Rh}$ thermocouple was placed just under the $\mathrm{Al}_{2} \mathrm{O}_{3}$ crucible containing the melted mixture. Both the thermocouple and the crucible were in the uniform temperature zone of the furnace (variation less than $\pm 2{ }^{\circ} \mathrm{C}$ ) to ensure that the temperature measured by thermocouple matched the temperature of the melt. When the spindle rotated at a constant speed in the coaxial device (the concrete dimension is shown in Fig. 2(b)), the torque exerted on the spindle was measured by the torque sensor, which was then converted to viscosity. Different shear rates were obtained by changing the rotation speed. The relationship between the rotational speed and the shear rate is shown in Eq. (3): ${ }^{16)}$

$$
\dot{\gamma}=2 \pi \frac{\delta_{c c}^{2}+1}{\delta_{c c}^{2}-1} n
$$

where $\delta_{c c}$ is the ratio of the radius of the outer cylinder (crucible) to that of the inner cylinder and $n$ is the rotational speed. The viscometer was calibrated regularly with standard castor oil.

The spindle typically used in this kind of rotation apparatus is cylindrical and made of a Mo-based material. This composition is, however, incompatible with $\mathrm{Fe}-\mathrm{C}$ melts due to the high solubility of Mo in $\mathrm{Fe}-\mathrm{C}$ melts. In order to accurately measure the viscosity of $\mathrm{Fe}-\mathrm{C}$ melts during solidification, the following improvements were made to the testing spindle: (1) New testing spindles were made of $\mathrm{ZrO}_{2}$ with the same shape and size of the traditional Mo spindles. $\mathrm{ZrO}_{2}$ is inert against $\mathrm{Fe}-\mathrm{C}$, allowing the new spindle to be rotated inside the $\mathrm{Fe}-\mathrm{C}$ melts without any erosion. (2) Miniature notch grooves with a depth of $1 \mathrm{~mm}$ were created around the cylindrical spindle in order to minimize the possible sliding conditions between the fluid containing particles and the spindles. The structure of the new spindle is shown in Fig. 2(c). To verify the accuracy of the viscosity measured

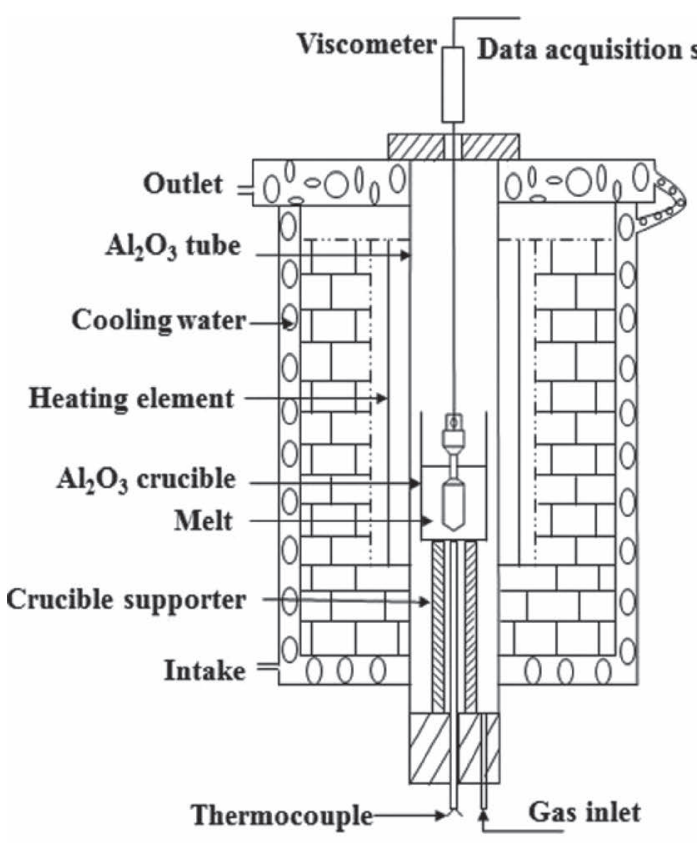

(a)

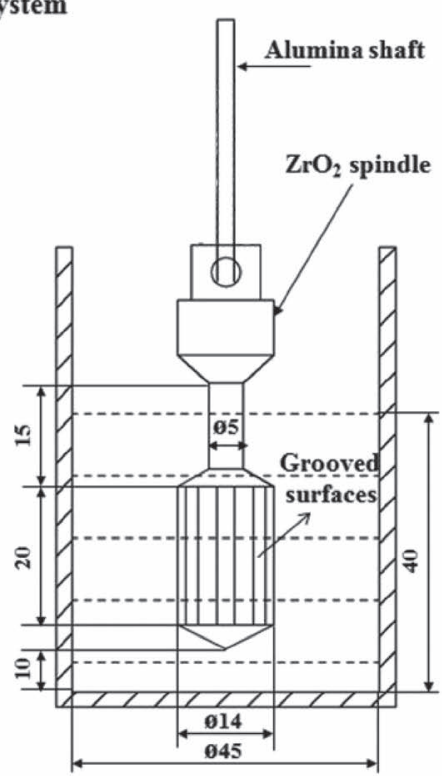

(b)

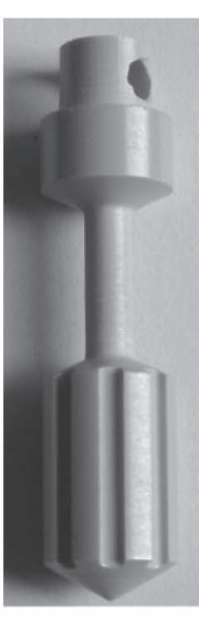

(c)

Fig. 2. Schematic diagram of experimental apparatus. (a) Viscosity measurement system. (b) Crucible and bob. (c) $\mathrm{ZrO}_{2}$ spindle. 
by the improved $\mathrm{ZrO}_{2}$ spindle, the standard Mo spindle and $\mathrm{ZrO}_{2}$ spindle were used to measure the viscosities of several known substances. The comparison of viscosities measured by the standard Mo spindle and the $\mathrm{ZrO}_{2}$ spindle showed that the measurements made with the new $\mathrm{ZrO}_{2}$ spindle were effectively identical to measurements made with the standard Mo spindle, verifying the accuracy of measurements made with the $\mathrm{ZrO}_{2}$ spindle (Fig. 3).

\subsubsection{Measuring the Apparent Viscosity of a Methyl Sili- cone Oil- $\mathrm{Al}_{2} \mathrm{O}_{3}$ Particle System}

$\mathrm{Al}_{2} \mathrm{O}_{3}$ particles were added to methyl silicon oil to obtain mixtures containing different volume fractions of $\mathrm{Al}_{2} \mathrm{O}_{3}$ particles $(0 \%, 7.14 \%, 14.28 \%, 21.42 \%, 28.56 \%$ and $35.7 \%)$. Thereafter, the viscosities of the two-phase mixtures were measured under different rotation speeds. Each measurement was repeated in triplicate, whose standard deviations were mostly less than $1 \%$. Finally, the average value was reported.

\subsubsection{Apparent Viscosity Measurements of $\mathrm{Fe}-\mathrm{C}$ Melts during Solidification}

During the viscosity measurements for $\mathrm{Fe}-\mathrm{C}$ melts, both the crucible and the spindle were aligned along the axis of the viscometer. After adjusting the position of the crucible, the $\mathrm{Fe}-\mathrm{C}$ alloy was completely melted by heating it above its liquidus temperature. This temperature was maintained for 60 minutes to ensure that the alloy was melted homogenously. A constant stream of pure $\operatorname{Ar}$ gas $(2 \mathrm{~L} / \mathrm{min})$ was injected into the furnace tube from the bottom of the apparatus throughout the experiment to protect the melt from potential side reactions. The stirring spindle was lowered into the melt slowly because of the low thermal shock resistance of $\mathrm{ZrO}_{2}$ until the bottom of the spindle was 10 $\mathrm{mm}$ away from the bottom of the crucible and centered within the melt. Then, the melt was sheared continuously at a set cooling rate until the viscosity of the melt was too high for the torque sensor to measure accurately. The melt was reheated above its liquidus temperature and the experiment was repeated with a different shear rate and a different cooling rate. The rheological conditions used in these

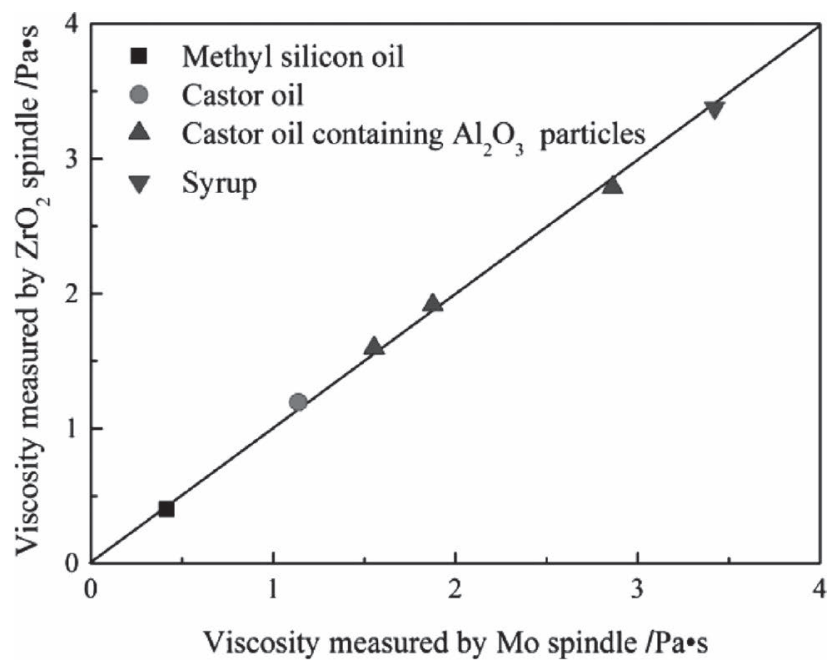

Fig. 3. Comparison of viscosities measured with the Mo spindle and $\mathrm{ZrO}_{2}$ spindle. experiments are shown in Table 2. Data from groups I, II, IV, and VI were used to derive the viscosity model equation, while experiments for group III and V were performed in succession to validate the accuracy of the proposed model.

In order to study the influence of the cooling rate and shear rate on the microstructure of the melt throughout the cooling and shearing process, when the temperature was lowered to a specified temperature, samples of melt were removed with a glass tube and quickly quenched in water. After the samples were polished with sandpaper and diamond polishing paste, the samples were thermally etched with alkaline picric acid aqueous solution $(2 \mathrm{~g}$ picric acid (AR, purity of higher than $99.8 \%$ ), $33 \mathrm{~g}$ sodium hydroxide (AR, purity of higher than $96.0 \%$ ) and $100 \mathrm{ml}$ distilled water at a corrosion temperature of approximately $95{ }^{\circ} \mathrm{C}$ for 30 minutes. The solidification microstructures of $\mathrm{Fe}-\mathrm{C}$ melts under different conditions were examined with an optical microscope (three ocular optical microscope 52XA, Shanghai Tu Ming Optical instrument Co., Ltd., Shanghai, China).

\section{Results and Discussion}

\subsection{Apparent Viscosity of Methyl Silicone Oil- $\mathrm{Al}_{2} \mathrm{O}_{3}$ Particle Systems}

Figures 4(a), 4(b), and 4(c) show the effects of the shear rate and the $\mathrm{Al}_{2} \mathrm{O}_{3}$ particle size and shape on the apparent viscosity of the methyl silicone oil- $\mathrm{Al}_{2} \mathrm{O}_{3}$ particle suspension. When the particle volume fraction was less than $15 \%$, there was no significant change in the viscosity of the two-phase mixture under different shear rates (Fig. 4(a)). The low-concentration particle suspension behaved like a traditional Newtonian fluid. An et al. ${ }^{17)}$ measured the apparent viscosity of an ABS (acrylonitrile butadiene styrene) particle-castor oil system and found that for a particle volume fraction lower than $15 \%$, the system still behaved as Newtonian fluid. At high particle volume fractions ( $>15 \%)$, the viscosity of the two-phase mixture gradually decreased as the shear rate increased. This phenomenon became more apparent as the particle volume fraction increased. The rheological behavior that viscosity decreases as increasing shear rate is known as shear thinning and such a system is defined as a pseudoplastic fluid. ${ }^{18)}$ This indicated that the methyl silicone oil- $\mathrm{Al}_{2} \mathrm{O}_{3}$ particle suspension behaves like a pseudoplastic fluid and shows shear thinning characteristic in case of the particle volume fractions higher than $15 \%$. Moreover, the apparent viscosity of the suspension increased as the size of the solid particles decreased (Fig. 4(b)). This relationship again was more apparent at higher particle concentrations. The shape of the particles can also affect the apparent viscosity of liquid-solid slurries (Fig. 4(c)). A lower apparent viscosity was observed for solidliquid mixtures with spherical particles. As known, the essential reason for liquids having viscosity is that there exist interactions between liquid molecules, creating shear deformation resistance. Likewise, in solid-liquid slurry mixtures, interacting forces between solid and solid particles, along with solid and liquid interactions, results in similar resistances. With the increase of particle volume fraction from having solid particles present, acting forces such as collision and cohesion, and external friction between solid particles become the main effect leading the increase of 

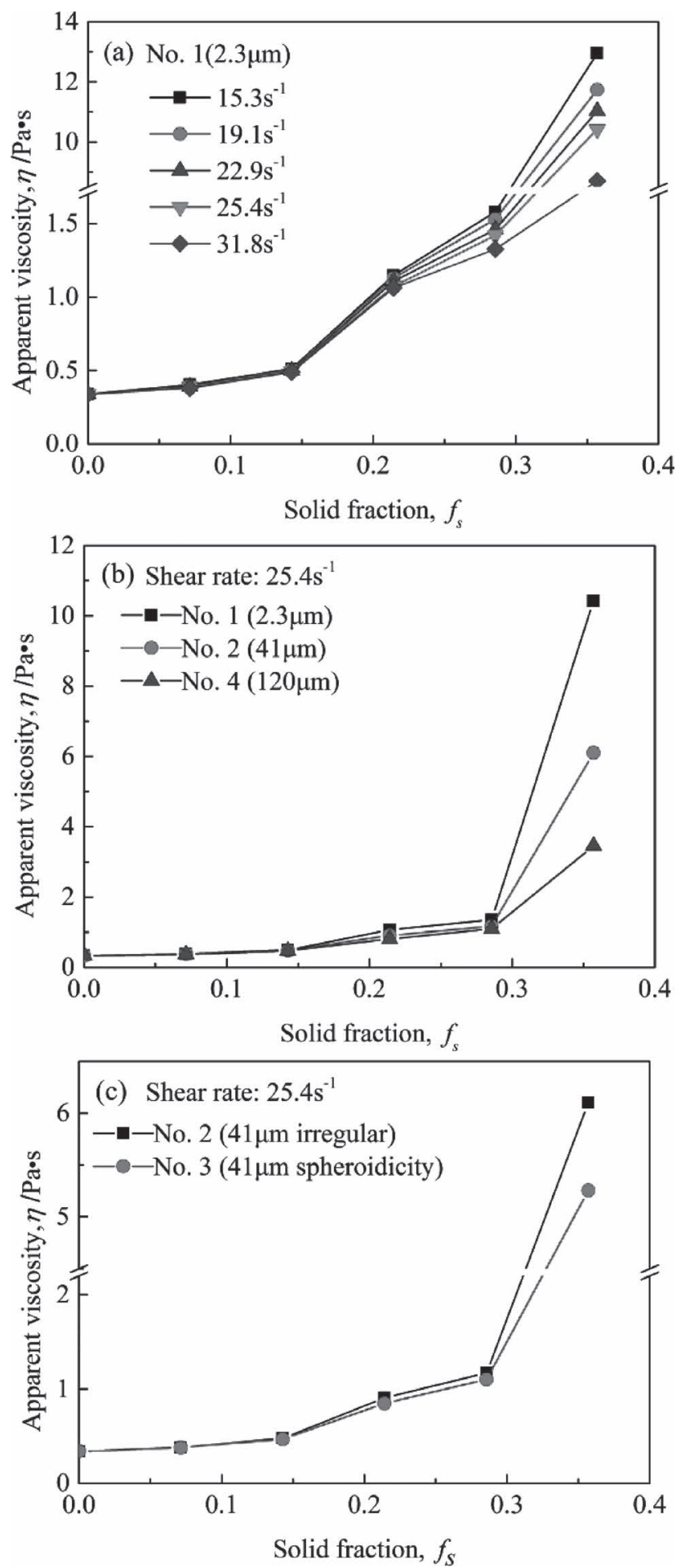

Fig. 4. Variations in the viscosity of methyl silicone oil- $\mathrm{Al}_{2} \mathrm{O}_{3}$ particle systems at different (a) shear rates, (b) sizes, and (c) shapes.

viscosity. And acting forces between solid particles are closely related to their shape and size. Stronger adhesion and cohesion forces typically occur between solid particles with a smaller size and a larger specific surface area. And external friction forces are smaller between particles of higher sphericity, resulting in a smaller resistance against shear deformation and a smaller apparent viscosity.

Using the viscosity results from the model methyl silicone oil- $\mathrm{Al}_{2} \mathrm{O}_{3}$ particle system, we attempted to calculate the viscosity of the suspension $(\eta)$ based on Eq. (1). Because the shape and size of the particles did not change during each
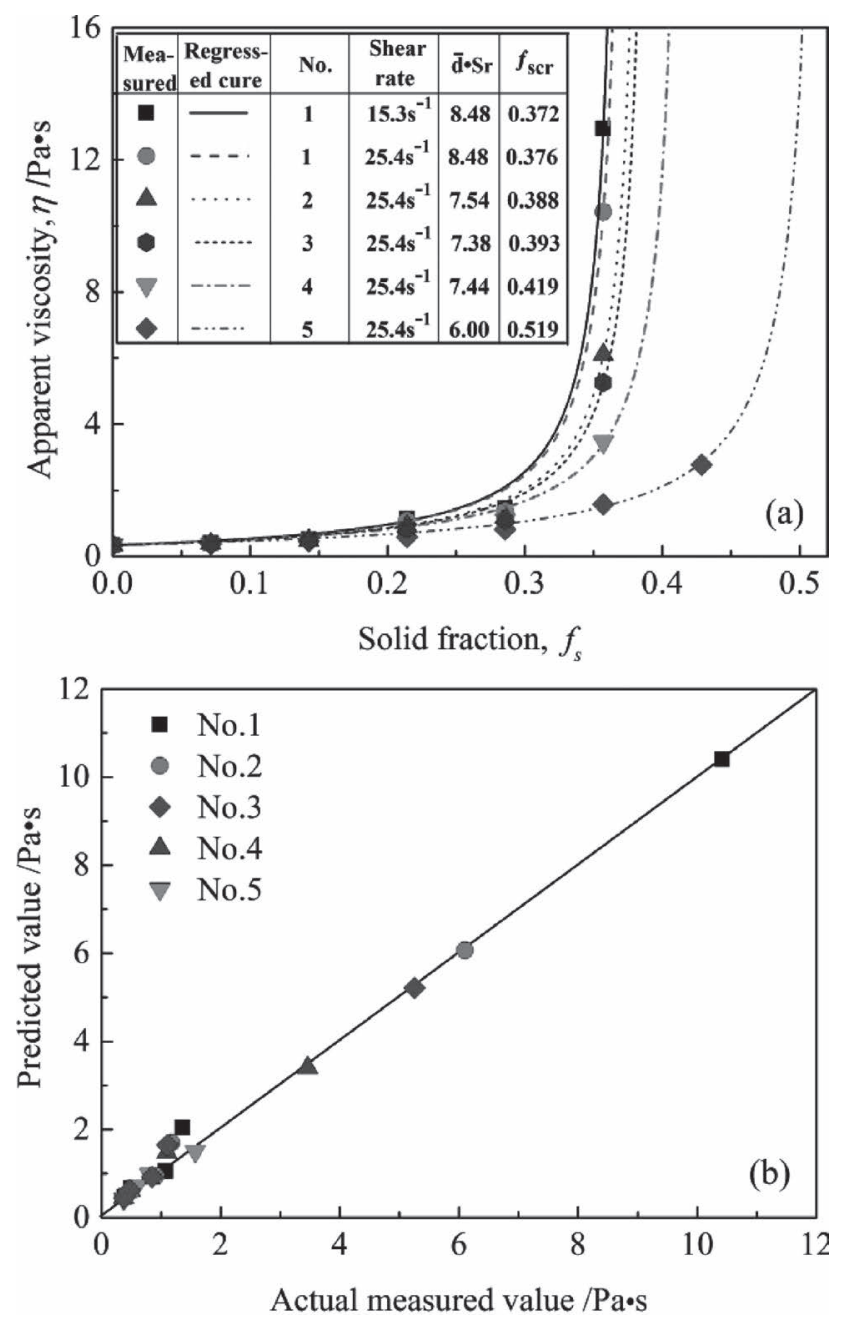

Fig. 5. (a) Calculated results for apparent viscosity based on Eq. (1). (b) Comparison of experimental and theoretical results for the apparent viscosity of the solid-liquid two-phase system.

experiment, $\bar{d} \cdot S_{\mathrm{r}}$ was fixed $\left(\bar{d}\right.$ and $S_{\mathrm{r}}$ were measured by a LMS-30 laser particles distribution instrument, Table 1), and $f_{\text {scr }}$ was calculated by a nonlinear least squares regression according to this experimental data. The results of the calculations are shown in Fig. 5(a). The apparent viscosity of the methyl silicon oil- $\mathrm{Al}_{2} \mathrm{O}_{3}$ particle system was well described by Eq. (1). The data shows that $f_{\text {scr }}$ increased with increasing shear rate. The larger and more spherically shaped the particles were, the smaller $\bar{d} \cdot S_{\mathrm{r}}$ became and the larger $f_{\text {scr }}$ became at the same shear rate. The physical properties of the particles not only affected $\bar{d} \cdot S_{\mathrm{r}}$, but also affected the critical solid fraction $f_{\text {scr, }}$, and thus impacted the apparent viscosity of the solid-liquid two-phase system. A comparison between the experimental data and predicted values calculated from Eq. (1) for the methyl silicone oil$\mathrm{Al}_{2} \mathrm{O}_{3}$ particle system shows a strong correlation between the model and the experimental results (Fig. 5(b)), indicating that the apparent viscosity of solid-liquid two-phase systems can be successfully simulated by the viscosity model proposed by Mori and Ototake. ${ }^{12)}$ 

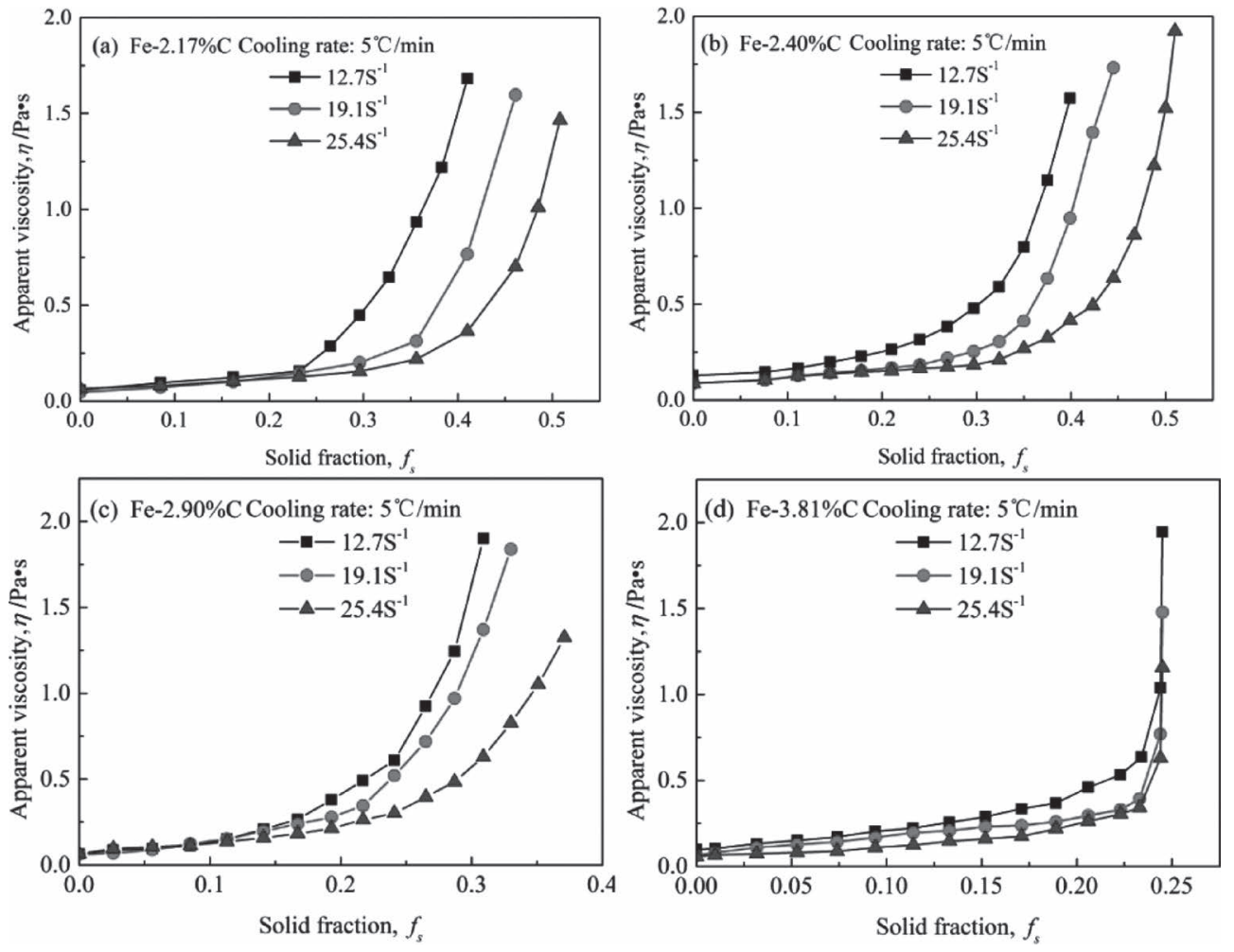

Fig. 6. Variations in the apparent viscosity of $\mathrm{Fe}-\mathrm{C}$ melts at a constant cooling rate and varying shear rates. (a) $\mathrm{Fe}-$ $2.17 \%$ C. (b) $\mathrm{Fe}-2.40 \%$ C. (c) $\mathrm{Fe}-2.90 \%$ C. (d) $\mathrm{Fe}-3.81 \% \mathrm{C}$.
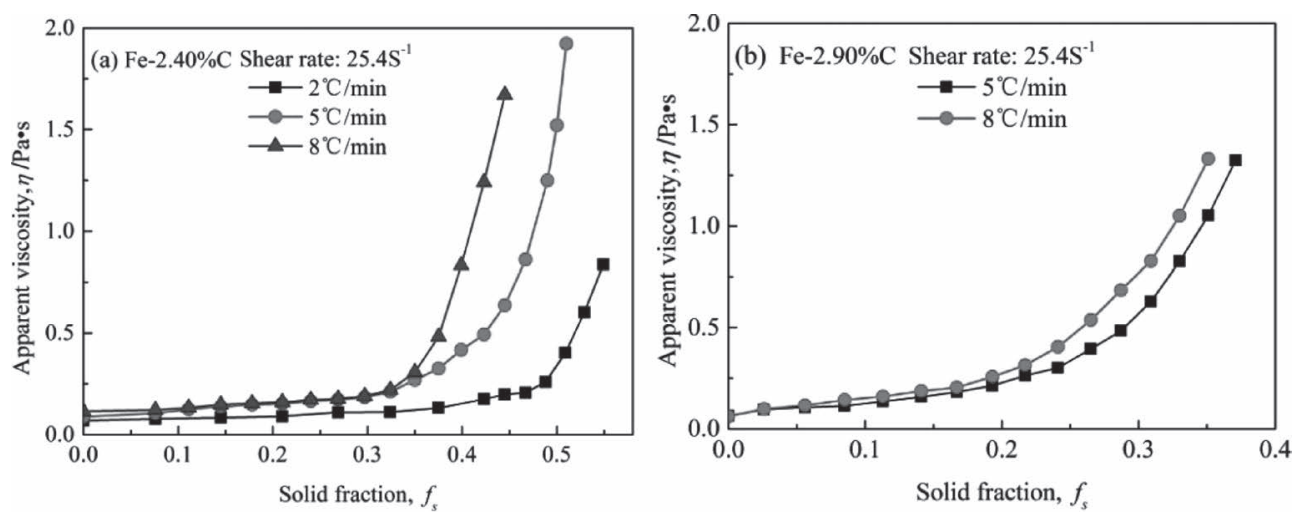

Fig. 7. Variations in the apparent viscosity of $\mathrm{Fe}-\mathrm{C}$ melts at a constant shear rate and varying cooling rates. (a) Fe$2.40 \%$ C. (b) $\mathrm{Fe}-2.90 \% \mathrm{C}$.

\subsection{Apparent Viscosity of Fe-C Melts during Solidifi- cation}

3.2.1. Effects of the Solid Fraction on the Apparent Viscosity of Fe-C Melts

Figures 6 and 7 show the relationship between the apparent viscosity of $\mathrm{Fe}-\mathrm{C}$ melts and solid fraction at different shear rates and cooling rates. The values for the solid fraction were obtained based on a $\mathrm{Fe}-\mathrm{C}$ phase diagram. ${ }^{19)}$

The solid fraction in $\mathrm{Fe}-\mathrm{C}$ melts has a strong influence on the apparent viscosity during solidification (Figs. 6 and 7). The apparent viscosity increased slowly as the solid fraction increased followed by a sharp increase when the solid fraction reached a certain critical value. When the solid fraction was low, the resistance against shear deformation came primarily from the viscosity of the liquid phase. As solidification continued, more solid particles precipitated out of the liquid phase, causing collisions and agglomerations between particles. The collision and friction forces between the solid particles increased and began to dominate the resistance forces within the system, resulting in a rapid increase in the apparent viscosity of the slurry. For the Fe-3.81\%C alloy (Fig. 6(d)), the narrow interval between the solid and liquid phases at a solid fraction of 0.245 caused a eutectic reaction to happen in the melt $\left(L \rightarrow \gamma+\mathrm{Fe}_{3} \mathrm{C}\right.$, shown in Table 2 ), resulting in no liquid phase and an apparent viscosity that increased sharply to infinity.

\subsubsection{Effect of Shear Rate on the Apparent Viscosity of $\mathrm{Fe}-\mathrm{C}$ Melts}

When the solid fraction of the $\mathrm{Fe}-\mathrm{C}$ melt was lower than $15 \%$, the apparent viscosity did not change with the variation of shear rate (Fig. 6), a characteristic indicative of Newtonian fluids. At solid fractions above $15 \%$, the apparent viscosity decreased as the shear rate increased, exhibit- 
ing the shear thinning behavior of a pseudoplastic fluid. ${ }^{18)}$ This behavior mimicked the apparent viscosity conditions seen in the model methyl silicone oil- $\mathrm{Al}_{2} \mathrm{O}_{3}$ particle system, indicating that these two solid-liquid suspension systems showed comparable apparent viscosities under similar conditions. The effect of shear rate on the apparent viscosity of $\mathrm{Fe}-\mathrm{C}$ melts during solidification became more apparent as the solid fraction increased. For the Fe-2.4\% C alloy (Fig. 6(b)), when the solid fraction was 0.21 , the apparent viscosity increased from 0.15 to $0.26 \mathrm{~Pa} \cdot \mathrm{s}$, growing by a factor of 1.73 , as the shear rate decreased from 25.4 to $12.7 \mathrm{~s}^{-1}$ (cooling rate $5^{\circ} \mathrm{C} / \mathrm{min}$ ). At a solid fraction of 0.40 , the apparent viscosity increased from 0.42 to $1.57 \mathrm{~Pa} \cdot \mathrm{s}$, growing by a factor of 3.74 .

\subsubsection{Effects of the Cooling Rate on the Apparent Viscos- ity of $\mathrm{Fe}-\mathrm{C}$ Melts}

As shown in Fig. 7, when the solid fraction and shear rate were held constant, increasing the cooling rate led to a higher apparent viscosity. The differences in the viscosities caused by variation of cooling rate increased as the solid fraction increased. For the Fe-2.4\%C alloy (Fig. 7(a)), at a
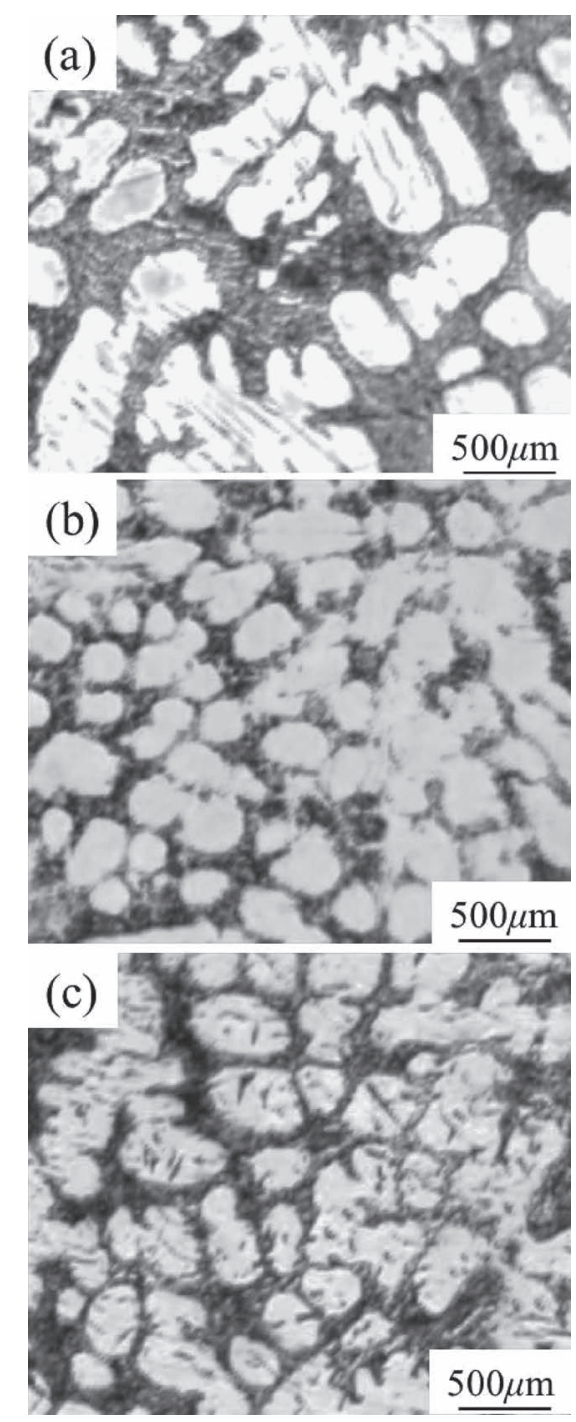

Fig. 8. Microstructures of water-quenched Fe-2.40\%C alloy $\left(f_{s}=\right.$ 0.32). (a) Cooling rate: $5^{\circ} \mathrm{C} / \mathrm{min}$, shear rate: $12.7 \mathrm{~s}^{-1}$. (b) Cooling rate: $5^{\circ} \mathrm{C} / \mathrm{min}$, shear rate: $25.4 \mathrm{~s}^{-1}$. (c) Cooling rate: $8^{\circ} \mathrm{C} / \mathrm{min}$, shear rate: $25.4 \mathrm{~s}^{-1}$. solid fraction of 0.21 , the apparent viscosity increased from 0.09 to $0.16 \mathrm{~Pa} \cdot \mathrm{s}$, growing by a factor of 1.78 , as the cooling rate increased from 2 to $8^{\circ} \mathrm{C} / \mathrm{min}$ (shear rate $25.4 \mathrm{~s}^{-1}$ ), while at a solid fraction of 0.42 , the viscosity increased from 0.17 to $1.24 \mathrm{~Pa} \cdot \mathrm{s}$, changing by a factor of 7.29 .

\subsubsection{Effects of Shear Rate and Cooling Rate on Micro- scopic Structures}

The microscopic structures in water-quenched Fe-2.40\%C
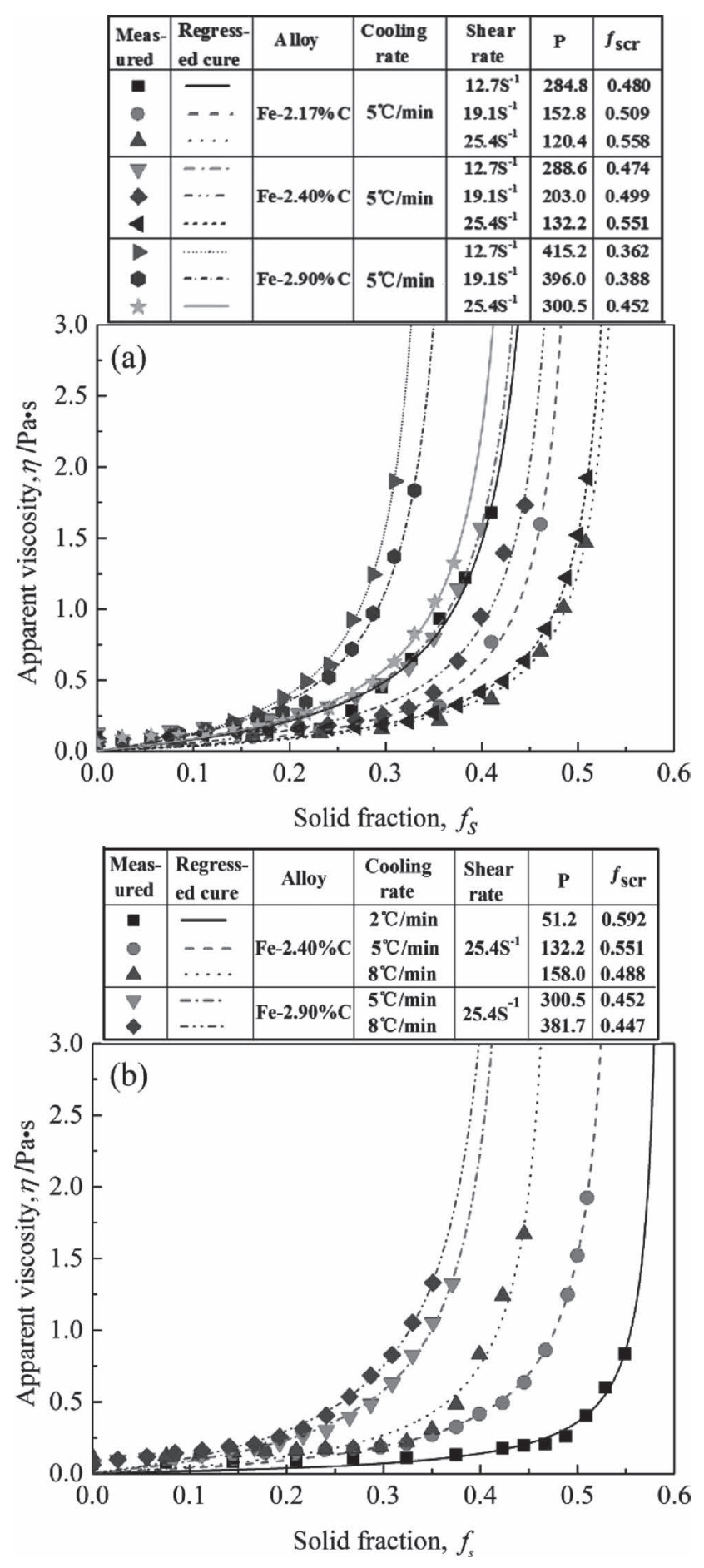

Fig. 9. Relationship between the apparent viscosity of Fe-C melts and the solid fraction. The curves were drawn using Eq. (2). Filled shapes represent experimental data points. (a) $\mathrm{Fe}-\mathrm{C}$ melts with the same cooling rate and varying compositions and shear rates. (b) $\mathrm{Fe}-\mathrm{C}$ melts with the same shear rate and varying compositions and cooling rates. 
alloys $\left(f_{s}=0.32\right)$ under different shear rates and cooling rates are shown in Fig. 8. The bright areas were the precipitated particles and the dark areas were the liquid matrix. For more accurately expressing the effects of cooling rate and shear rate on the shape of precipitated particles, degree of sphericity was used to quantitatively characterize the shape factor. The degree of sphericity of the primary solid particles for various conditions (shown in Fig. 8) was calculated using image analysis software ImageJ, with values of $0.76,0.82$, and 0.80 in Figs. 8(a), 8(b), and 8(c), respectively. It clearly indicates that a higher shear rate and a lower cooling rate led to particles with higher sphericity degree. Similar tendency was reported in the microstructural features of semi-solid AZ91D magnesium alloy, ${ }^{20)}$ where the primary particles were rounder with a higher shear rate and lower cooling rate. Under traditional non-stirring solidification conditions, dendrites are the primary form of the solid phase of $\mathrm{Fe}-\mathrm{C}$ melt. However, the primary solid phase precipitated from the liquid phase tends to gradually change its shape from dendritic to non-dendritic when stirred continuously as the particles fracture, bent, and agglomerated. The formation of non-dendritic structures (reflecting the morphology of primary solid phase) is more favorable with higher stirring force and a longer stirring time, and a high shear rate means high stirring force, while a low cooling rate means a longer time to stir under the same condition. Therefore, a higher degree of sphericity of the primary solid phase occurs at a higher shear rate and a lower cooling rate, resulting in a decrease in the apparent viscosity of $\mathrm{Fe}-\mathrm{C}$ melts (Figs. 6(b) and 7(a)). This was consistent with the results of the methyl silicone oil- $\mathrm{Al}_{2} \mathrm{O}_{3}$ particle system (Fig. 4(c)), where a smaller apparent viscosity was observed with spherical
$\mathrm{Al}_{2} \mathrm{O}_{3}$ particles.

\subsection{Apparent Viscosity Model for Fe-C Melts during Solidification}

$\mathrm{Fe}-\mathrm{C}$ melts can be modeled as a solid-liquid two-phase suspension system, with solid particles constantly precipitating from the melt during solidification. The size and shape of the solid phase particles change continuously during solidification, i.e. $\bar{d} \cdot S_{\mathrm{r}}$ changes, so variations in the apparent viscosity of $\mathrm{Fe}-\mathrm{C}$ melts in this study can be described by Eq. (2). P represents the geometry parameter of the solid particles precipitated from the liquid phase, changing as the solidification conditions change. $\eta_{L}$ refers to the viscosity of the liquid metal. For Fe-C melts, $\eta_{L}$ was roughly 0.0043 $\mathrm{Pa} \cdot \mathrm{s}$, as calculated from equation ${ }^{21)}$ proposed by Hirai.

The calculations for the apparent viscosity of $\mathrm{Fe}-\mathrm{C}$ melts with varying solid fractions based on Eq. (2) are shown in Fig. 9, where the values of $\mathrm{P}$ and $f_{\text {scr }}$ for each case were obtained through regression based on the least squares principle. Based on the correlation between the experimental data and the theoretical modeling curves, we were confident in the use of Eq. (2) to represent the relationship between the apparent viscosity and solid fraction of $\mathrm{Fe}-\mathrm{C}$ melts during solidification. The values of $\mathrm{P}$ and $f_{\text {scr }}$ were strongly dependent on the cooling rate, shear rate and carbon composition of the $\mathrm{Fe}-\mathrm{C}$ melts, taking these key factors into consideration when using this prediction model. The effects of the shear rate and cooling rate on the calculated values of $P$ and $f_{\text {scr }}$ are shown in Fig. 10. P increased with decreasing shear rate and increasing cooling rate. The solid phase particles that precipitated during solidification became more spherical as the shear rate increased and the cooling rate decreased,
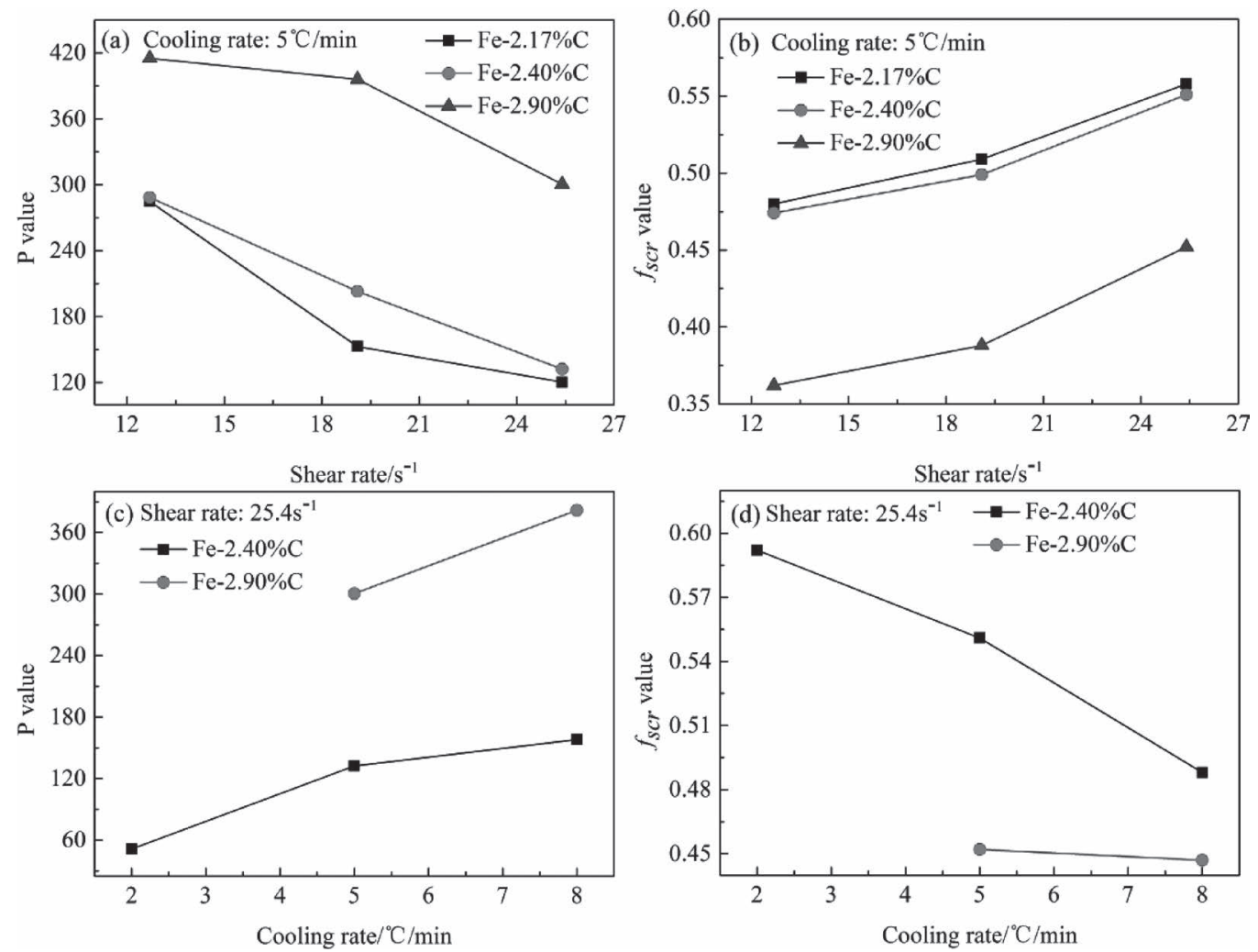

Fig. 10. Variations in $\mathrm{P}$ and $f_{\text {scr }}$ values with changes in shear rate and cooling rate for various alloys. (a) $\mathrm{P}$ value $v s$ shear rate. (b) $f_{\text {scr }}$ value $v s$ shear rate. (c) P value $v s$ cooling rate. (d) $f_{\text {scr }}$ value $v s$ cooling rate. 
leading to a larger geometry parameter of the particles $\left(\bar{d} \cdot S_{\mathrm{r}}\right)$. The microstructures seen in Fig. 8 confirmed the effects of the shear rate and cooling rate on particle shape and size. While $f_{\text {scr }}$ decreased with decreasing shear rate and increasing cooling rate. In addition, Fig. 10 suggests that $\mathrm{P}$ and $f_{\text {scr }}$ are strongly dependent on the carbon content of the $\mathrm{Fe}-\mathrm{C}$ melts. $\mathrm{P}$ increased with increasing carbon content while $f_{\text {scr }}$ decreased with increasing carbon content. Previous study ${ }^{7)}$ showed that a higher solute concentration in an alloy led to the formation of rosette-type crystals, resulting in particles with relatively large surface areas and irregular, non-spherical shapes. Therefore, the geometrical shape parameter of the crystals " $\mathrm{P}$ " became larger with increasing solute concentrations in melts and the volume fraction of liquid trapped between the primary crystals increased, and thus the critical solid fraction, $f_{\text {scr }}$ became smaller. Similar to the methyl silicon oil- $\mathrm{Al}_{2} \mathrm{O}_{3}$ particle system, different solidification conditions affected $\mathrm{P}\left(\bar{d} \cdot S_{\mathrm{r}}\right)$ and the critical solid fraction $f_{\text {scr }}$ through the physical properties of the particles, and thus impacted the apparent viscosity of the solid-liquid two-phase system.

When using Eq. (2) to simulate the variation in the apparent viscosity in $\mathrm{Fe}-\mathrm{C}$ melts during solidification, the main parameters $\mathrm{P}$ and $f_{\text {scr }}$ are primarily influenced by the cooling rate, shear rate and carbon content of the alloy. Hiria et al. ${ }^{7)}$ studied the apparent viscosity of semi-solid Al-10\% Cu alloy using Eq. (2) and showed that $\mathrm{P}$ and $f_{\text {scr }}$ had an exponential relationship with the solidification rate and shear rate. Here, the exponential relationship between $\mathrm{P}$ and $f_{\text {scr }}$ and the solidification rate and shear rate are shown in Eqs. (4) and (5). In these equations, the $\mathrm{Fe}-2.4 \% \mathrm{C}$ melt was used as an example.

$$
\begin{gathered}
\mathrm{P}=\alpha C^{0.66} \dot{\gamma}^{-1.23} \ldots \ldots \\
f_{\text {scr }}=0.646-\beta C^{0.79} \dot{\gamma}^{-0.70}
\end{gathered}
$$

where $\alpha$ and $\beta$ are constants, $C$ is the average solidification rate $\left(d f_{\mathrm{s}} / d t\left(s^{-1}\right)\right)$, and $\dot{\gamma}$ is the shear rate $\left(\mathrm{s}^{-1}\right)$.

For the other Fe-C melts, it was assumed that $\mathrm{P}$ and $f_{\text {scr }}$ had the same exponential relationship with the solidification rate and shear rate, while the values of $\alpha$ and $\beta$ reflected the effect of the carbon content on $\mathrm{P}$ and $f_{\text {scr }}$, respectively. Accordingly, $\mathrm{P}$ and $f_{\text {scr }}$ in $\mathrm{Fe}-\mathrm{C}$ melts with various carbon contents were calculated using Eqs. (4) and (5), respectively (Table 3).

Equations (6) and (7) were used to approximate the quantitative relationship between $\alpha$ and $\beta$ and the carbon content of each melt.

$$
\begin{gathered}
\alpha=6.52 \times 10^{4} \times \mathrm{X}^{3.25} \\
\beta=31.86 \times \mathrm{X}^{3.01}
\end{gathered}
$$

where $\mathrm{X}$ is the percentage of carbon $(\%)$.

Table 3. The values of $\alpha$ and $\beta$ in Eqs. (4) and (5).

\begin{tabular}{cccc}
\hline Alloy & Carbon content (mass $\%)$ & $\alpha$ & $\beta$ \\
\hline $\mathrm{Fe}-2.17 \% \mathrm{C}$ & 2.17 & $8.68 \times 10^{5}$ & 357.51 \\
$\mathrm{Fe}-2.40 \% \mathrm{C}$ & 2.40 & $1.02 \times 10^{6}$ & 410.85 \\
$\mathrm{Fe}-2.90 \% \mathrm{C}$ & 2.90 & $2.08 \times 10^{6}$ & 791.67 \\
\hline
\end{tabular}

Equations (6) and (7) were substituted into Eqs. (4) and (5), respectively to obtain Eqs. (8) and (9).

$$
\begin{array}{r}
\mathrm{P}=6.52 \times 10^{4} \times \mathrm{X}^{3.25} \mathrm{C}^{0.66} \dot{\gamma}^{-1.23} \ldots . \\
f_{\text {scr }}=0.646-31.86 \times \mathrm{X}^{3.01} C^{0.79} \dot{\gamma}^{-0.70}
\end{array}
$$

A comparison between the values for $\mathrm{P}$ and $f_{\text {scr }}$ calculated by Eqs. (8) and (9) and the values determined with Eq. (2) (Fig. 9) is shown in Fig. 11. The correlation between the values determined by each method confirmed the viability of
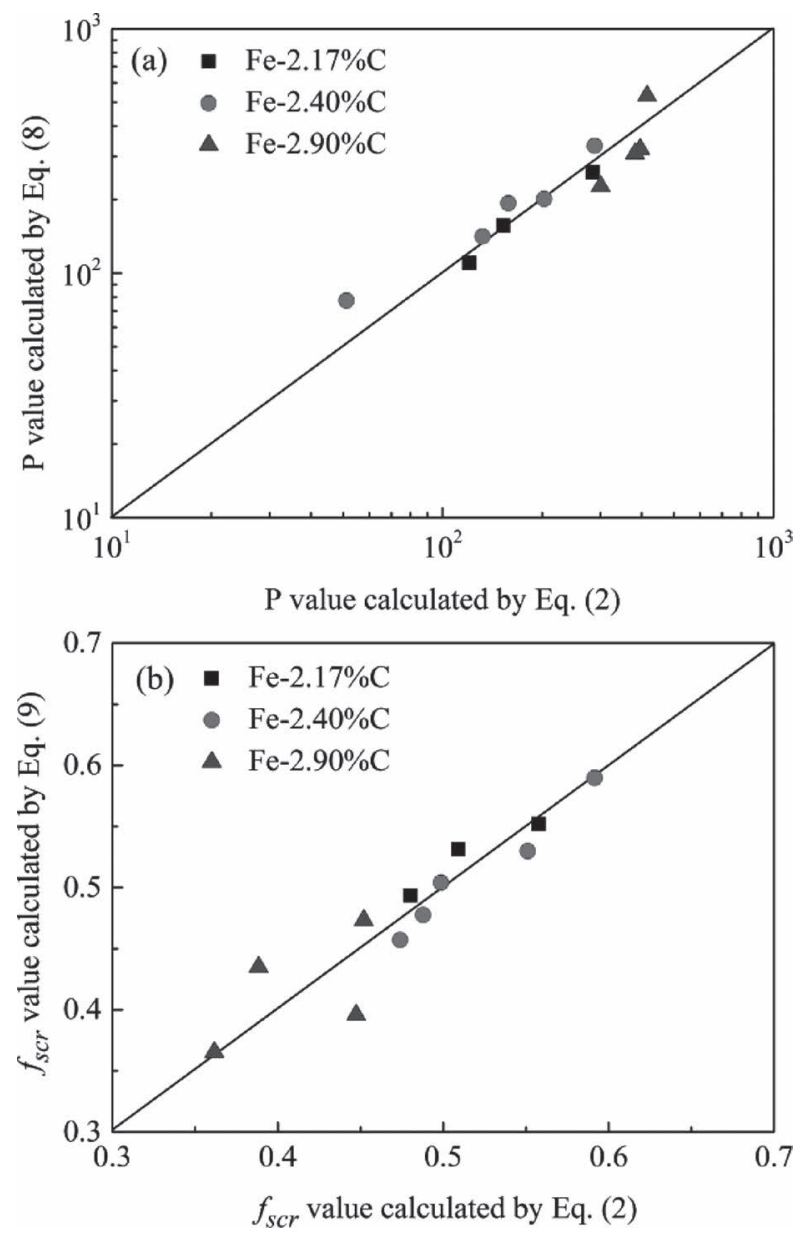

Fig. 11. Comparison between the (a) $\mathrm{P}$ and (b) $f_{\text {scr }}$ values calculated by Eqs. (8) and (9) and the values calculated by Eq. (2).

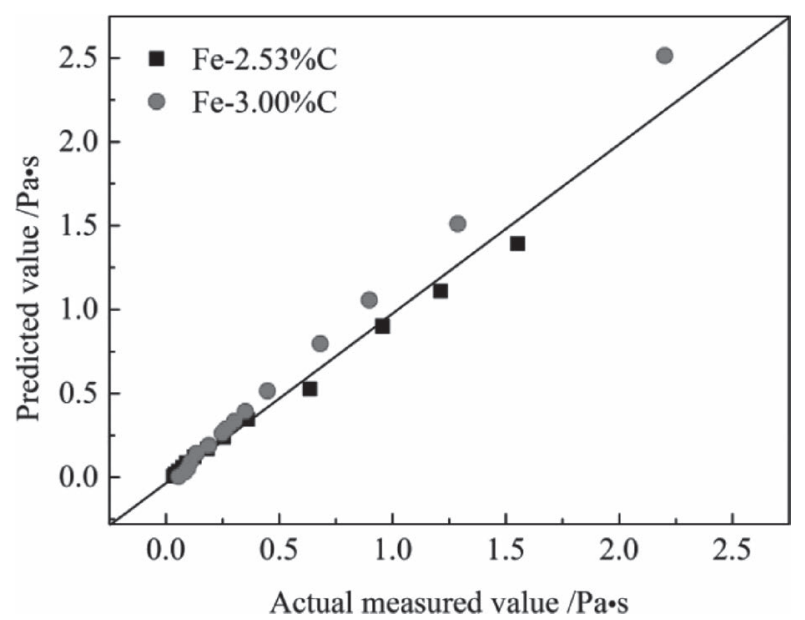

Fig. 12. Comparison between experimental and predicted values. 
using Eqs. (8) and (9) to describe the relationships between $\mathrm{P}$ and $f_{\text {scr }}$ and the solidification rate, shear rate, and carbon content of $\mathrm{Fe}-\mathrm{C}$ melts.

Combining Eqs. (2), (8), and (9), the relationship between the apparent viscosity of $\mathrm{Fe}-\mathrm{C}$ melts during solidification can be expressed as follows:

$$
\eta=\eta_{L}\left[1+\frac{6.52 \times 10^{4} \times \mathrm{X}^{3.25} C^{0.66} \dot{\gamma}^{-1.23}}{2\left(\frac{1}{f_{s}}-\frac{1}{0.646-31.86 \times \mathrm{X}^{3.01} C^{0.79} \dot{\gamma}^{-0.70}}\right)}\right] \ldots
$$

In order to verify Eq. (10), experiments for Groups III and $\mathrm{V}$ (Table 2) were carried out and the apparent viscosity during the solidification for $\mathrm{Fe}-2.53 \% \mathrm{C}$ and $\mathrm{Fe}-3 \% \mathrm{C}$ melts was measured. The comparison between the experimental values and predicted values calculated by Eq. (10) is shown in Fig. 12. Values for both melts agreed with the Eq. (10) values, indicating that it was possible to accurately predict the apparent viscosity of $\mathrm{Fe}-\mathrm{C}$ melts during solidification using Eq. (10) under some experimental situations.

\section{Conclusions}

The apparent viscosity of methyl silicon oil- $\mathrm{Al}_{2} \mathrm{O}_{3}$ particle systems and $\mathrm{Fe}-\mathrm{C}$ melts during solidification along with the effects of key factors that influence apparent viscosity were thoroughly investigated in this study. Based on our findings, the following conclusions were obtained:

(1) In a model methyl silicon oil- $\mathrm{Al}_{2} \mathrm{O}_{3}$ particle system, it was found that when the volume fraction of $\mathrm{Al}_{2} \mathrm{O}_{3}$ particles in the mixture was less than $15 \%$, the fluid behaved as Newtonian fluid. When the volume fraction was $15 \%$ or greater, the fluid exhibited shear thinning, characteristic of pseudoplastic fluids. Smaller particles with irregular shapes led to a higher apparent viscosity of the system. The model proposed by Mori and Ototake (Eq. (1)) was used to express the variation tendency of the apparent viscosity of the methyl silicon oil- $\mathrm{Al}_{2} \mathrm{O}_{3}$ particle system.

(2) Similar to the methyl silicon oil- $\mathrm{Al}_{2} \mathrm{O}_{3}$ model system, when the solid fraction of $\mathrm{Fe}-\mathrm{C}$ melts was lower than $15 \%$, the melts behaved as Newtonian fluids. When the solid fraction rose to $15 \%$ or more, the melt exhibited characteristics of pseudoplastic fluids. In addition, the apparent viscosity increased as the cooling rate increased and the shear rate decreased. The microscopic structures of the cooled samples show that with increasing shear rate and decreasing cooling rate, the shape of the precipitated particles became more spherical.

(3) The apparent viscosities of $\mathrm{Fe}-\mathrm{C}$ melts during solidification can be described by a modified version of Mori and Ototake's model (Eq. (2)). The value of P based on Eq. (2) increased with decreasing shear rate, increasing cooling rate and increasing carbon content in $\mathrm{Fe}-\mathrm{C}$ melts. A larger $f_{\text {scr }}$ value could be obtained with smaller $\mathrm{P}$ values. Under this research situations, the apparent viscosity of $\mathrm{Fe}-\mathrm{C}$ melts during solidification could be predicted by using the following equation.

$$
\eta=\eta_{L}\left[1+\frac{6.52 \times 10^{4} \times \mathrm{X}^{3.25} C^{0.66} \dot{\gamma}^{-1.23}}{2\left(\frac{1}{f_{s}}-\frac{1}{0.646-31.86 \times \mathrm{X}^{3.01} C^{0.79} \dot{\gamma}^{-0.70}}\right)}\right]
$$

\section{Acknowledgments}

The authors would like to acknowledge the financial support from National Natural Science Foundation of China (No. 51234001).

\section{REFERENCES}

1) J. Cheng, J. Grobner, N. Hort, K. U. Kainer and R. Schmid-Fetzer: Meas. Sci. Technol., 25 (2014), 1.

2) P. A. Joly and R. Mehrabian: J. Mater. Sci., 11 (1976), 1393.

3) M. Hirai, K. Takebayashi, Y. Yoshikawa and R. Yamaguchi: ISIJ Int., 33 (1993), 405.

4) Y. S. Yang and C.-Y. A. Tsao: J. Mater. Sci., 32 (1997), 2087.

5) H. I. Chen, J. C. Chen and J. J. Liao: Mater. Sci. Eng., A, 487 (2008), 114.

6) A. Shibutani, K. Arihara and Y. Nakamura: Tetsu-to-Hagané, 66 (1980), 1550.

7) M. Hirai, K. Takebayashi and Y. Yoshikawa: ISIJ Int., 33 (1993), 1182.

8) A. Einstein: Ann. Phys., 19 (1906), 289

9) A. Einstein: Ann. Phys., 34 (1911), 591.

10) J. Happel: J. Appl. Phys., 28 (1957), 1288.

11) D. G. Thomas: J. Colloid Sci., 20 (1965), 267.

12) Y. Mori and N. Ototake: Chem. Eng., 20 (1956), 488.

13) S. Matsuzaki and T. Orimoto: Tetsu-to-Hagané, 99 (2013), 493.

14) I. Ohnaka, J. D. Zhu, A. Sugiyama and F. Kinoshita: Mater. Sci. Eng., 33 (2012), 1

15) M. Kohga and Y. Hagihara: J. Soc. Powder Technol., 35 (1998), 482.

16) K. Sołek1, M. Korolczuk-Hejnak1 and M. Karbowniczek1: Arch. Metall. Mater., 56 (2011), 595.

17) Z. Q. An, Y. L. Zhang, Q. L and Z. C. Guo: Mater. Sci. Eng. Powder Metall., 20 (2015), 46.

18) T. G. Mezger: Rheology Handbook, For Users of Rotational and Oscillatory Rheometers, Vincentz Network, Hannover, (2006), 34.

19) R. Tanaka: Tetsu-to-Hagané, 53 (1967), 1586.

20) W. M. Mao, Z. S. Zhen, S. J. Yan and X. Y. Zhong: J. Mater. Sci. Technol., 20 (2004), 580.

21) M. Hirai: ISlJ Int., 33 (1993), 281. 